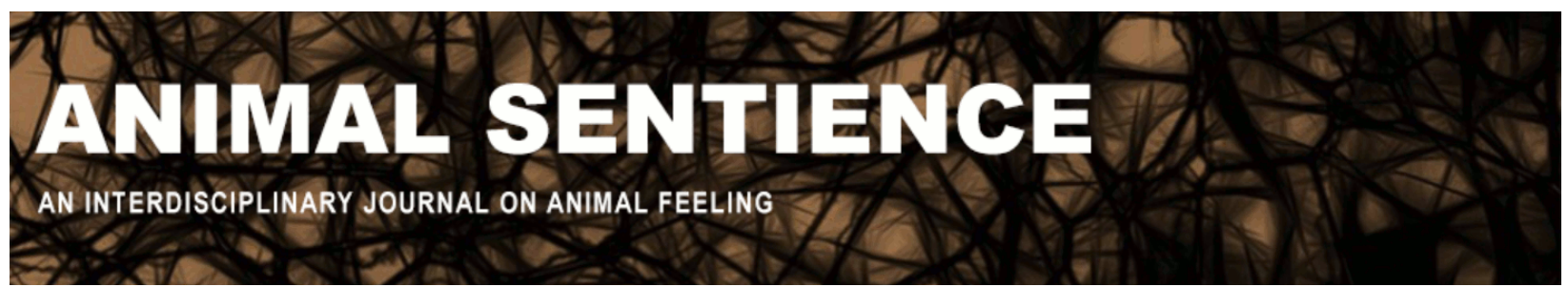

Marino, Lori (2018) Thinking about thinking chickens. Animal Sentience 17(15) DOI: $10.51291 / 2377-7478.1373$

Date of submission: 2018-09-30

Date of acceptance: 2018-10-10

(c) (i)




\title{
Thinking about thinking chickens
}

Response to Commentary on Marino on Thinking Chickens

\author{
Lori Marino \\ Kimmela Center for Animal Advocacy, Utah
}

\begin{abstract}
This response focuses on three major conceptual threads that run through the peer commentary on my target article: (1) how the use of chickens influences our views of them, (2) whether education is effective, and (3) what components of chicken psychology are most relevant to understanding who chickens are.
\end{abstract}

\begin{abstract}
Lori Marino is a neuroscientist, former faculty affiliate at the Emory Center for Ethics, President of the Whale Sanctuary Project, and Executive Director of the Kimmela Center for Animal Advocacy. She has authored over 130 publications on dolphin and whale brain evolution and anatomy; intelligence and self-awareness; and the effects of captivity on social mammals, including cetaceans, elephants, and primates. She worked with the Nonhuman Rights Project and is featured in the films Blackfish and Unlocking The Cage. Website
\end{abstract}

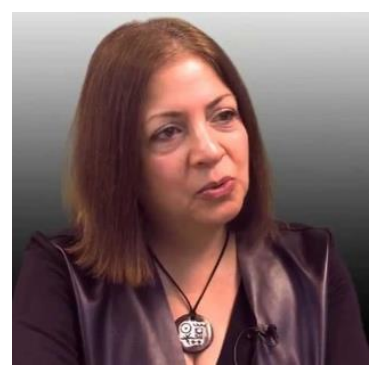

I would like to start by expressing my appreciation for all of the points of view and insights offered by my peers in their commentaries on my target article (Marino 2017a,b). In this response, I identify and discuss the three major threads running through the commentaries: (1) how commoditization affects our views of chickens and other farmed animals, (2) whether education about animals' intelligence influences how we treat them, and (3) the need to understand who chickens are.

\section{The role of commoditization in our views of chickens and other farmed animals}

The preponderant point of agreement across the commentaries is that chickens are not treated as well as they could be and that much of this is an outcome of perceiving chickens as objects, commodities, and resources rather than real birds who are invested in the way their lives unfold. Hodson makes the central point that commoditization drives our attitudes toward farmed animals to provide relief from the cognitive dissonance and emotional distress of promoting the widespread abuse inherent in eating them. Merskin, Rollin, and Jenni make strong points about the policy implications of the findings in the target article and mention the many ways chickens and other farmed animals have become invisible to systematic animal welfare regulations. Rollin explicitly acknowledges that chickens "have fallen through the cracks," mainly because of commoditization. He also reminds us that the scientific community has often played a significant role in the objectification of chickens and other farmed animals by promoting the misconception that science must be blind to the consciousness, intelligence, and, yes, the inherent value of nonhuman research subjects. 
Freeman urges us to be aware that the language we use in communicating about other animals, including chickens, shapes our perceptions of them. I appreciate her recognizing that I have deliberately chosen to refer to chickens in respectful and realistic ways, e.g., discussing emotion instead of affect or personality instead of temperament traits. In my view, it is more parsimonious and authentic to recognize the continuity in psychology across species and to use terms that, when appropriate, reflect that reality. Balcombe has also made a cogent case for this stance towards fishes, another group of commoditized animals routinely given short shrift by both the public and the scientific community.

\section{Does education about animals' intelligence influence how we treat them?}

It is a major challenge to apply findings on nonhuman animal intelligence to changing human attitudes and behavior. Basic research should be valued for its contribution to general knowledge, but scientific findings also have important implications for real-world issues. One of the fundamental tenets of the scientific method is that current theories and ideas need to be revised in light of new evidence. This is relevant in both basic and applied research. We need to revise our theories and hypotheses, but also to change our own behavior when applying them. Findings concerning who chickens are - their capabilities, sensitivities, and preferences - should alter and refine how we treat them. Is public education an effective way to change public attitudes and behavior? In my target article, I provide evidence that believing animals are sentient or have a "mind" is a strong predictor of attitudes towards animal use, whereas Bottomley \& Laughlan and Hodson cite evidence that learning about animal intelligence has little impact on moral concern. How do we square these two seemingly different conclusions?

Bottomley \& Laughlan report that in the case of animals that we enjoy eating and wearing, additional psychological factors (i.e., rationalizations) come into play to allay moral concern. For example, when people want to eat meat yet still see themselves as making ethical choices, they don't take animal intelligence into consideration. Bottomley \& Laughlan suggest that providing opportunities to meet chickens personally might help people discover how engaging and sensitive chickens are, yet even these kinds of experiences are unlikely to change behavior in the long-term. Friere \& Hazel cite evidence that when students are given the opportunity to train chickens, their perception of how intelligent and sentient they are does change (Hazel et al., 2015). Are those changes in attitude lasting and acted on in everyday behavior? Bottomley \& Laughlan suggest that a more effective strategy might be to link chicken intelligence more directly with who is on the plate, leaving those who wish to keep eating chickens less "room" to escape the inevitable feelings of discomfort. This is already happening in public education, particularly through The Someone Project (Farm Sanctuary), of which my chicken review is a part. But changing behavior in the face of so many strong psychological human defenses is difficult, and frankly, frustrating.

Hodson agrees that evidence about chicken intelligence should change attitudes but that the psychological literature on motivated reasoning and group-based dominance suggests that change is unlikely; the more likely effect is strong push-back. Hodson notes that the same kinds of psychological forces are at work when people are confronted with evidence of climate change. Humans are strongly motivated to dismiss evidence that would create "an inconvenient truth" for them in their everyday lives, as the findings on both chicken intelligence and climate change do. 
What to conclude? I admit I am not sure. I agree that education is not likely to be the most expedient way to change how we treat other animals, but I do think that, at the very least, objective scientific information should be made available to all who wish to learn more about other animals. Education is necessary but not sufficient to inspire behavioral change. Personal experiences can also go a long way for those who are open to them. Sanctuaries can create such opportunities. But as Bottomley \& Laughlan and Hodson point out, we must also recognize and deal with the inherent biases and limitations of human psychology that will curb the effectiveness of any efforts to induce change.

\section{The range of topics relevant to understanding who chickens are}

Many commenters addressed the broad range of topics relevant to understanding chickens. Some, such as Rogers and Vallortigara, suggested that I had not covered enough topics; others, such as Andrews, argued that I covered more topics than necessary to make my point. I appreciate all these insights. Both Rogers and Vallortigara argued that I should have included the copious scientific literature on chicken lateralization in my review. Although I am aware of this literature, I did not regard it as directly relevant to understanding the complexity of chicken minds; that may have been a mistake. Lateralization concerns the way information is processed and how that level of organization is reflected in behavior through perceptual asymmetries and other characteristics. Some aspects of human laterality (e.g., handedness) do not seem as relevant to human intelligence as others, such as language asymmetries. I suspect that chicken laterality has both aspects too; I should have included at least some of the literature on laterality most relevant to intelligence, particularly in light of Rogers's intriguing suggestion that laterality is germane to animal welfare issues. She (Rogers, 2010) has pointed out that laterality may be related to positive and negative judgement biases in chickens and other animals, and also that known brain asymmetries might be shifted towards the positive by environmental factors.

Vallortigara makes further points about sentience and "higher cognition," citing Siemann and Deluis (1993) to the effect that sentience (i.e., having felt experience) has little to do with advanced cognition. Those authors had reported that humans can successfully complete quite complex cognitive tasks, such as transitive inference, subconsciously, and had concluded that implicit transitive inference must be an ancient trait, not requiring conscious awareness. We have long-known, however, that many complex cognitive abilities are performed subconsciously by humans and probably other animals. My point is that the popular distinction between "associative" and "cognitive" processes may not be a useful way to understand intelligence and behavior. It is doubtful that logical inference is one monolithic process. Many authors have a more complex view of cognition in humans and other animals according to which the context of learning and testing shapes the components involved (Allen, 2006; Libben and Titone, 2008; Zentall, 2018). A similar point is made by Friere $\boldsymbol{\&}$ Hazel: "there is believed to be an interplay between fundamental cognitive processes (e.g., associative learning ...) and higher-level capacities" (Shettleworth 2010). Chiandetti notes that if only simple chained associative processes are used to probe chicken intelligence, then there may be much that is missed about their abilities.

Johnsson takes issue with my claim that chicken domestication has been focused mostly on industrial production traits rather than psychological traits. He provides evidence that chickens have been selected for emotionality and fearfulness. I would add, however, that 
many of the so-called psychological traits in domesticated chickens are not specifically selected for so much as they are part of a suite of traits that may come along with selection for production. (See Young, 2002, on featherless chickens as the new trend in chicken production.) To respond to Johnsson's "minor quibble": Yes, intense artificial selection is genetic manipulation.

Andrews suggests that some of the work I presented may have been overstated or unrelated to the main issue. I cannot agree. Andrews creates a strawman by criticizing my inclusion of perceptual abilities in a review on intelligence. Nowhere in the paper do I claim that perceptual abilities should be the foundation for moral standing, which is the basis for Andrew's criticism. The stated purpose of my paper was this:

The purpose of this paper is twofold: first, to gain a better understanding of the minds of chickens from the best scientific literature, separating fact from fiction; two, to identify compelling areas for future noninvasive research. (Marino 2017a, p. 128)

Andrews agrees that the paper achieves these two purposes. (Commentaries on whether a specific line of research is relevant to moral standing according to formal ethical theories are certainly pertinent, but they are not the focus the paper.) Andrews's other criticisms are not to be dismissed but are matters of interpretation of the scientific literature (see discussion above on similar comments by Vallortigara). I appreciate Andrews's suggestions about what might make a cogent argument for moral standing from the scientific literature on chickens and agree that emotions are especially germane to the issue. I would welcome further discussion - theoretical as well as practical - of ways to make the ethical case for treating chickens as the intelligent, sentient, sensitive beings they are.

\section{Conclusion}

All the commentators agree that there is a need for more accurate information about chicken behavior and that chickens could be treated far more humanely than they are. There are differences about what humane treatment for chickens should be. Some favor better welfare within the existing system of factory farming; some are clearly advocating invasive and terminal research. These are all parts of the commoditization that seems to play such a major role in how we perceive and treat chickens. I am nonetheless grateful that a full range of views has been represented here.

Several commenters point out that we are still far from understanding what kinds of educational and experiential interventions would be effective in changing human behavior toward chickens and other farmed animals. We have yet to find a way to change most people's attitudes, let alone their actual behavior. 


\section{References}

Allen, C. (2006) Transitive inference in animals: Reasoning or conditioned associations. Rational Animals: 175-185.

Andrews, K. (2018) Chicken minds and moral standing. Animal Sentience 17(14).

Balcombe, J. (2017) Chicken of the sea. Animal Sentience 17(11).

Bottomley, E., \& Loughnan, S. (2017) Chickening out of change: Will knowing more about thinking chickens change public perceptions? Animal Sentience 17(8).

Chiandetti, C. (2018) Chickens play to the crowd. Animal Sentience 17(13).

Farm Sanctuary. The Someone Project.

Freeman, C. P. (2017) Misperceiving and underestimating the ubiquitous chicken. Animal Sentience 17(7).

Hazel, S. J., O'Dwyer, L., \& Ryan, T. (2015). “Chickens are a lot smarter than I originally thought": Changes in student attitudes to chickens following a chicken training class. Animals, 5(3): 821-837.

Hodson, G. (2017) What is the pressing "animal question" about? Thinking/feeling capacity or exploitability? Animal Sentience 17(12).

Jenni, K. (2017) Scientific advances and moral inertia. Animal Sentience 17(9).

Johnsson, M. (2017) Changes in behavior and emotion under chicken domestication. Animal Sentience $17(10)$.

Libben, M. \& Titone, D. (2008) The role of awareness and working memory in human transitive inference. Behavioural Processes 77: 43-54.

Marino, L. (2017a). Thinking chickens: A literature review of cognition, emotion, and behavior in the domestic chicken. Animal Cognition, 20(2): 127-141.

Marino, L. (2017b) The inconvenient truth about thinking chickens. Animal Sentience 17(1).

Merskin, D. (2017) Getting to the other side. Animal Sentience 17(5).

Rogers, L. J. (2010). Relevance of brain and behavioural lateralization to animal welfare. Applied Animal Behaviour Science, 127(1-2): 1-11.

Rogers, L. J. (2017) Chickens' brains, like ours, are lateralized. Animal Sentience 17(3).

Rollin, B. (2017) Raising consciousness about chicken consciousness. Animal Sentience $17(2)$.

Shettleworth, S. J. (2010) Cognition, evolution, and behavior. Oxford University Press.

Siemann, M., \& Delius, J. D. (1993) Implicit deductive responding in humans. Naturwissenschaften, 80(8): 364-366.

Vallortigara, G. (2017) Sentience does not require "higher" cognition. Animal Sentience 17(6).

Young, E. (2002) Featherless chicken creates flap. New Scientist, May 21.

Zentall, T. (2018) The value of research in comparative cognition. International Journal of Comparative Psychology, 31: 1-17. 